\title{
Antimicrobial activity and substantivity of Uncaria tomentosa in infected root canal dentin
}

\section{Daniel Rodrigo HERRERA(a) Jorge Enrique DURAND-RAMIREZ(a) Amanda FALCÃO(a) Emmanuel João Leal Nogueira da SILVA ${ }^{(b)}$ \\ Elizabete Brasil dos SANTOS(c) \\ Brenda Paula Figueiredo de \\ Almeida GOMES(a)}

(a) Universidade Estadual de Campinas UNICAMP, Department of Restorative Dentistry, Endodontic Division, Piracicaba, SP, Brazil

(b) Universidade do Grande Rio UNIGRANRIO, Health and Science Center, Department of Endodontics, Rio de Janeiro, RJ, Brazil.

(c) Universidade Estadual de Ponta Grossa - UEPG, Department of Dentistry, Ponta Grossa, PR, Brazil.

Declaration of Interests: The authors certify that they have no commercial or associative interest that represents a conflict of interest in connection with the manuscript.

Corresponding Author:

Daniel Rodrigo Herrera

E-mail: dani_hm76@hotmail.com

DOI: 10.1590/1807-3107BOR-2016.vol30.0061

Submitted: Oct 07, 2015

Accepted for publication: Jan 11, 2016

Last revision: Feb 22, 2016
Abstract: The aim of this study was to analyze the antimicrobial activity and substantivity of Uncaria tomentosa Willd DC (cat's claw, CC) in root dentin contaminated with Enterococcus faecalis. Forty-eight human premolars were contaminated with E. faecalis (ATCC 29212) and randomly divided into four groups according to the irrigant used during chemomechanical preparation (CMP): CC group: $2 \%$ CC gel; $\mathrm{CHX}$ group: $2 \%$ chlorhexidine digluconate gel ( $\mathrm{CHX}$ ); $\mathrm{NaOCl}$ group: $5.25 \%$ sodium hypochlorite (NaOCl); and SS group: sterile saline (SS). Microbiological samples were collected before (S1) and after (S2) CMP and after 7 days (S3). Colony-forming units (CFU/mL) at the different sampling times and comparisons among the groups were statistically analyzed by Wilcoxon and Kruskal-Wallis tests ( $p<0.05)$. Significant bacterial reduction was achieved in all groups after CMP $(\mathrm{p}<0.05)$. Results show no significant difference between S3 and S2 ( $p>0.05)$ in the CC and CHX groups. Bacterial load was higher in S3 than in S2 samples $(p<0.05)$ in the $\mathrm{NaOCl}$ and SS groups. Our results suggest antibacterial effect of $2 \%$ $C C$ gel against $E$. faecalis in infected dentin, in addition to antibacterial substantivity of $2 \%$ CC and $2 \%$ CHX up to 7 days.

Keywords: Cat's Claw; Sodium Hypochlorite; Chlorhexidine; Enterococcus faecalis.

\section{Introduction}

Endodontic therapy aims to remove diseased tissue, eliminate bacteria from the root canal system, and prevent recontamination after treatment. These objectives are achieved by biomechanical cleaning and shaping, by obturation of the root canal system, and by placement of coronal restoration. ${ }^{1}$ Unfortunately, because of the anatomical complexity of the root canal system, organic and inorganic residues and bacteria cannot be completely removed and often persist. ${ }^{2,3,4}$ For this reason, a wide variety of chemical substances has been tested to minimize bacteria, necrotic tissue and residual debris, ${ }^{1,2,3}$ particularly sodium hypochlorite $(\mathrm{NaOCl})$, the most widely used endodontic irrigant, ${ }^{5}$ and chlorhexidine (CHX), another auxiliary chemical substance used in endodontic therapy. None of these irrigants has all of the characteristics of an ideal irrigant.

A desirable property of endodontic irrigants concerns their capacity to be absorbed on negatively charged surfaces in the mouth (e.g., enamel, dentin, cement, mucosa, restorative materials), being slowly released from these 
retention sites and therefore maintaining prolonged antimicrobial activity. ${ }^{5}$ This process is known as substantivity, and only $\mathrm{CHX}$ and tetracycline have had this property so far. ${ }^{6}$ Thus, several studies have examined the activity and potential application of other chemical substances, including natural products.7

Uncaria tomentosa (Willd) DC, which is known as cat's claw (CC) because of the small curved thorns in its leaf axil, is one of the most promising medicinal herbs from the Amazon Rainforest. It has anti-inflammatory, antiviral, antibacterial, antioxidant, and immunomodulatory activity. ${ }^{8}$ Moreover, $U$. tomentosa has not shown toxicity at concentrations between $1-10 \%$ in the neutral red assay, kenacid blue total protein assay, tetrazolium assay (MTT), and microtox test. ${ }^{9}$ These properties have allowed the Brazilian Unified Public Health System (Sistema Único de Saúde -SUS) to include it on its list of phytotherapeutic agents for anti-inflammatory treatment.

However, no studies have examined the antimicrobial potential of CC in an infected dentin model. Therefore, the present in vitro study was conducted to analyze the antibacterial activity and substantivity of $2 \%$ CC gel in infected root canal dentin. The null hypothesis assumes that there is no significant difference between 2\% CC gel, 2\% CHX gel, $5.25 \% \mathrm{NaOCl}$, and sterile saline solution (SS) in antibacterial activity and substantivity against Enterococcus faecalis.

\section{Methodology}

\section{Selection and standardization of specimens}

The protocol (155/2014) for sample collection was approved by the Human Research Ethics Committee of the Piracicaba Dental School. Forty-eight human single-rooted premolars were used in the study. The crowns of all teeth were removed with a water-cooled diamond saw (Diamond Wafering Blade, Series 15LC, Buehler, USA) and their roots were standardized to a length of 15 millimeters. The root canals and the apical foramen were enlarged with K-files (Dentsply-Maillefer, Ballaigues, Switzerland) up to size 25, under irrigation with distilled water. The smear layer formed in the canal walls during instrumentation was removed using an ultrasonic bath with 17\% EDTA for $10 \mathrm{~min}$ followed by $5.25 \% \mathrm{NaOCl}$ for $10 \mathrm{~min}, 5 \%$ sodium thiosulfate for $10 \mathrm{~min}$ and, finally, distilled water for 1 hour. The specimens, in groups of five, were placed into glass tubes containing $5 \mathrm{~mL}$ of SS and autoclaved for complete specimen sterilization.

\section{Specimen contamination and experimental groups}

E. faecalis (ATCC 29212) was subcultured onto BHI-blood agar plates (BHI, Lab M, Bury, UK) to obtain fresh colonies, which were adjusted spectrophotometrically at $800 \mathrm{~nm}$ in tubes containing $5 \mathrm{~mL}$ of SS to match the turbidity of $1.5 \times 10^{8} \mathrm{CFU} \mathrm{mL}^{-1}$ and used as the test microorganism. The root canals were individually contaminated for 21 days in tubes containing $5 \mathrm{~mL}$ of $E$. faecalis suspension.

The specimens were randomly divided into four groups ( $n=12)$ using the Research Randomizer Software (available at http://www.randomizer.org) to define the irrigant to be used during chemomechanical preparation (CMP): CC group: $2 \%$ CC gel; $\mathrm{CHX}$ group: $2 \%$ CHX gel (Endogel, Itapetininga, Brazil); $\mathrm{NaOCl}$ group: $5.25 \%$ $\mathrm{NaOCl}$; and SS group: SS. A freeze-dried extract of CC (Fleming Manipulações, Ponta Grossa, Brazil) was used to prepare a hydroalcoholic solution of CC mixed with $1 \%$ hydroxyethylcellulose (Natrosol) as a gel base.

\section{CMP and microbiological sampling}

After contamination, initial samples (S1) were collected using sterile paper points retained in position during 60 seconds. Ten-fold serial dilutions were prepared up to $10^{-4}$ in tubes containing BHI broth (Lab M, Bury, UK) and $50 \mu \mathrm{L}$ was plated onto BHI-blood agar Petri plates and incubated $\left(37^{\circ} \mathrm{C} / 48 \mathrm{~h}\right)$. Thereafter, colony-forming units (CFU) were visually quantified for each plate.

After S1, all specimens were instrumented using the MTwo rotary system (VDW, Munich, Germany) up to \# 40.04 file. Prior to the use of a new instrument, the canal was irrigated with $1 \mathrm{~mL}$ of the specific substance (CC, $\mathrm{CHX}, \mathrm{NaOCl}$, or SS). After the use of each instrument, $1 \mathrm{~mL}$ of SS was used for irrigation in all groups. After CMP, all specimens received irrigation with 17\% EDTA for $3 \mathrm{~min}$ and a final flush with $5 \mathrm{~mL}$ of SS. Root canals were lightly dried and 
the second samples (S2) were collected and processed as described previously.

Afterwards, the specimens were kept filled with SS and transferred onto plates with 24 flat-bottomed wells (Corning Cell Culture, Corning, USA) and the root canal orifices were sealed using previously disinfected wax. The wells were filled with $\mathrm{BHI}$ broth to the surface of the specimens and incubated $\left(37^{\circ} \mathrm{C} / 7\right.$ days) before sampling and processed as described previously.

Before that, the second and third samples (S2 and S3) were serially diluted and plated. The paper points corresponding to $\mathrm{CHX}$ and $\mathrm{NaOCl}$ groups were individually soaked in their specific neutralizer [5\% Tween 80 and $0.07 \%(\mathrm{w} / \mathrm{v})$ lecithin, for the $\mathrm{CHX}$ group; $5 \%$ sodium thiosulfate, for the $\mathrm{NaOCl}$ group] for $1 \mathrm{~min}$ to avoid any residual antimicrobial activity during culture procedures.

\section{Statistical analysis}

The data collected from CFU concentrations were statistically analyzed using the BioEstat 5.3 software (Belém, Pará, Brazil). The Shapiro-Wilk test showed that the data distribution deviated from normality. The Friedman test was performed to compare the amount of bacteria at each sampling time (S1, S2, and S3). The Wilcoxon test was used when significant differences were found between different sampling times. Comparison of the root canal treatment groups (CC, $\mathrm{CHX}, \mathrm{NaOCl}$, and SS) was performed by using the Kruskal-Wallis test. The significance level was set at $5 \%(p<0.05)$.

\section{Results}

Table provides an overview of the amount of culturable bacteria $(\mathrm{CFU} / \mathrm{mL})$. The percentage values of bacterial reduction found in all groups tested at different sampling times are shown in Figure.

Culturable bacteria were recovered from 100\% $(48 / 48)$ of the baseline root canal samples (S1). Significant median percentage values of bacterial reduction were obtained in all groups after CMP compared with the baseline samples $(\mathrm{p}<0.05)$. Negative bacterial culture was detected in nine S2 samples $(75.00 \%)$ of the CC group, in 10 samples (83.33\%) of the $\mathrm{CHX}$ and $\mathrm{NaOCl}$ groups, and in two samples $(16.66 \%)$ of the SS group.
Regarding antibacterial substantivity, no statistically significant difference was observed between the median values of bacterial reduction found in S3 compared with $\mathrm{S} 2$ samples in the CC and CHX groups ( $\mathrm{p}>0.05)$. The $\mathrm{NaOCl}$ and SS groups showed a higher bacterial load in S3 compared with S2 samples ( $\mathrm{p}<0.05)$.

\section{Discussion}

The compounds found in CC include oxindole alkaloids, triterpenes, vegetable steroids, phenolic compounds, glycosides, tannin, and flavonoids. These compounds may be related to the antimicrobial activity of $\mathrm{CC}^{10,11}$ Isopteropodine- $\mathrm{HCl}$, a pentacyclic oxindole alkaloid isolated from the bark of the plant, has been shown to be the most potent of the tested compounds, with antibacterial activity against Gram-positive bacteria. ${ }^{12}$

In this study, CC was tested against E. faecalis, which is a facultative anaerobic Gram-positive coccus present in $24 \%-74 \%$ of asymptomatic and persistent endodontic infections. ${ }^{13}$ Some of the possible reasons contributing to the resistance of $E$. faecalis to endodontic therapy are its ability to survive long periods of nutritional deprivation and its ability to contaminate dentinal tubules and bind to dentin and collagen. ${ }^{13,14}$

Specific neutralizers were used to avoid any residual antimicrobial activity of $\mathrm{CHX}$ and $\mathrm{NaOCl}$ during culture procedures. Since there are no reports about CC inhibition, pilot assays were performed to assess the residual antimicrobial activity of CC in paper points. No inhibitory effect was observed after the use of $17 \%$ EDTA.

The data obtained in the present study revealed that regardless of the irrigant used during CMP, there was a significant reduction in the bacterial load. Although this bacterial load reduction was substantial (above $90 \%$ ) for all groups, culturable bacteria were still detected in $90 \%$ of the root canals irrigated with SS (control group), highlighting the importance of the antimicrobial activity of chemical substances. When $\mathrm{CC}, \mathrm{CHX}$, or $\mathrm{NaOCl}$ were used as irrigants, negative bacterial culture was detected in 29 out of 36 samples $(80.56 \%)$. The limited ability of root canal treatment to eliminate bacteria has been demonstrated by previous studies in which culturable bacteria were recovered in $20 \%-60 \%$ of the infected teeth after CMP. ${ }^{15,16,17,18,19}$ 


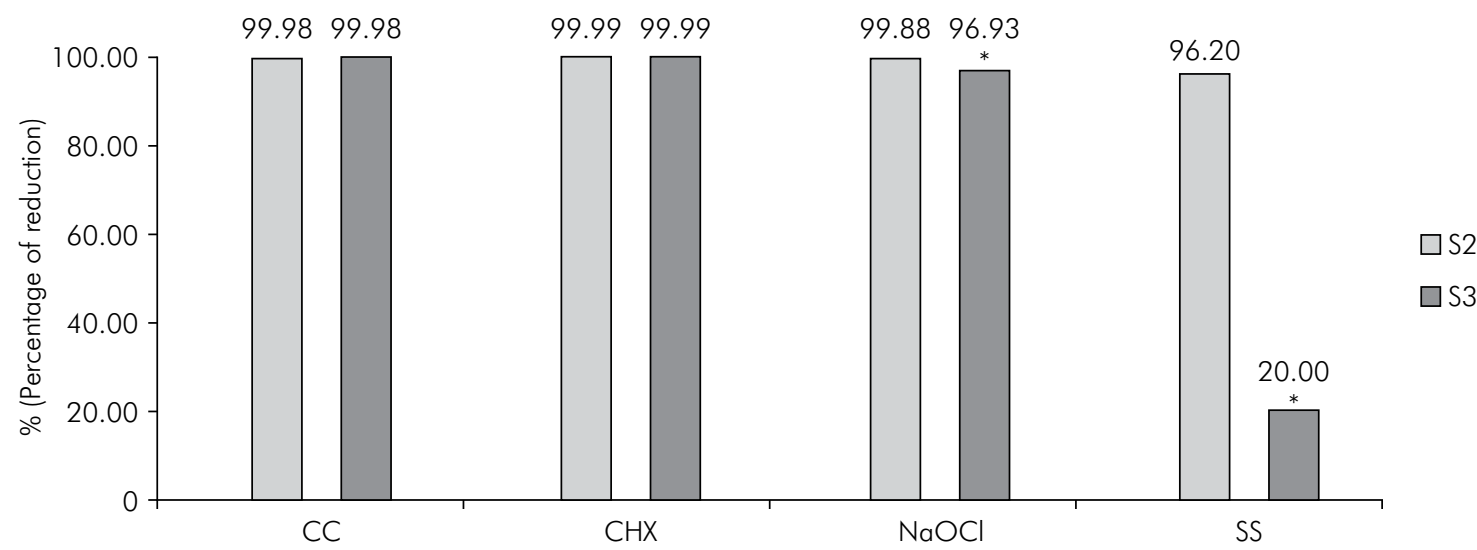

CFU: Colony-forming units; CC: cat's claw; CHX: chlorhexidine; $\mathrm{NaOCl}$ : sodium hypochlorite; SS: sterile saline.

Figure. Distribution of percentage values found for the reduction of culturable bacteria after CMP (S2) and after 7 days (S3), as well as statistical significance $(*)$.

Table. Median values of bacterial reduction (CFU/mL) obtained from CC, $\mathrm{CHX}, \mathrm{NaOCl}$, and SS.

\begin{tabular}{lccc}
\hline & \multicolumn{1}{c}{ S1 } & S2 & S3 \\
\hline $\mathrm{CC}$ & $1.15 \times 10^{5}\left(2.4 \times 10^{4}-1.9 \times 10^{5}\right)$ & $1.8 \times 10(0-2.1 \times 10)$ & $1.9 \times 10(0-2.3 \times 10)$ \\
$\mathrm{CHX}$ & $1.30 \times 10^{5}\left(4.8 \times 10^{4}-1.8 \times 10^{5}\right)$ & $1.6 \times 10(0-2.0 \times 10)$ & $1.8 \times 10(0-2.2 \times 10)$ \\
$\mathrm{NaOCl}$ & $1.11 \times 10^{5}\left(9.5 \times 10^{3}-2.1 \times 10^{5}\right)$ & $1.3 \times 10(0-2.3 \times 10)$ & $3.4 \times 10^{3}\left(0-3.7 \times 10^{4}\right)$ \\
$\mathrm{SS}$ & $1.00 \times 10^{5}\left(2.1 \times 10^{4}-1.6 \times 10^{5}\right)$ & $3.8 \times 10^{3}\left(0-4.2 \times 10^{4}\right)$ & $8.0 \times 10^{4}\left(2.7 \times 10^{4}-3.9 \times 10^{5}\right)$ \\
\hline
\end{tabular}

CFU: Colony-forming units; CC: cat's claw; CHX: chlorhexidine; NaOCl: sodium hypochlorite; SS: sterile saline; $\mathrm{S} 1$ : before chemomechanical preparation (CMP); S2: after CMP; S3: after 7 days.

Regarding the substantivity of chemical substances used in this study, CC and CHX prevented bacterial recontamination up to 7 days. Root canals irrigated with $\mathrm{NaOCl}$ were recontaminated, showing that the antimicrobial activity of $\mathrm{NaOCl}$ could have a limited use in CMP. The data on the substantivity of CHX are consistent with those of previous studies that reported antimicrobial activity for 7 days, ${ }^{20} 21$ days, ${ }^{21} 4$ weeks, ${ }^{6}$ and up to 12 weeks. ${ }^{22}$ Further studies are necessary to understand how CC chemical molecules interact with dentin to maintain its antimicrobial activity.

Further studies are also necessary to assess the CC capability to neutralize bacterial endotoxins, antimicrobial activity against multi-species biofilms, and possible chemical interactions with other substances commonly used in endodontic therapy.

\section{Conclusion}

In conclusion, our results confirm the antibacterial effect of $2 \%$ CC gel against $E$. faecalis in infected root canal dentin. This study also showed the antibacterial substantivity of $2 \%$ CC and $2 \%$ CHX.

\section{Acknowledgments}

We would like to thank Maicon Ricardo Zieberg Passini for technical support. The authors deny any conflicts of interest. Also, there is no financial affiliation (e.g., employment, direct payment, stockholdings, retainers, consulting arrangements, patent licensing arrangements, or honoraria), or involvement with any commercial organization with direct financial interest in the subject or materials discussed in this manuscript, nor have any such arrangements existed in the past 3 years. Any other potential conflict of interest is disclosed. This work was supported by the Brazilian agencies Fundação de Amparo à Pesquisa do Estado de São Paulo - FAPESP (13/23061-5) and Conselho Nacional de Desenvolvimento Científico e Tecnológico - CNPq (308162/2014-5). 


\section{References}

1. Byström A, Sundqvist G. Bacteriologic evaluation of the efficacy of mechanical root canal instrumentation in endodontic therapy. Scand J Dent Res. 1981;89(4):321-8.

2. Ørstavik D, Haapasalo M. Disinfection by endodontic irrigants and dressings of experimentally infected dentinal tubules. Endod Dent Traumatol. 1990;6(4):142-9. doi:10.1111/j.1600-9657.1990.tb00409.x

3. Peters LB, Wesselink PR. Periapical healing of endodontically treated teeth in one and two visits obturated in the presence or absence of detectable microorganisms. Int Endod J. 2002;35(8):660-7. doi:10.1046/j.1365-2591.2002.00541.x

4. Gomes BPFA, Vianna ME, Zaia AA, Almeida JFA, Souza-Filho FJ, Ferraz CCR. Chlorhexidine in endodontics. Braz Dent J. 2013;24(2):89-102. doi:10.1590/0103-6440201302188

5. Block SS. Disinfection, Sterilization and Preservation. 5th ed. Philadelphia (USA): Lippincott Williams \& Wilkins; 1991. Chapter 15, Chlorhexidine; p. 321-36.

6. Khademi AA, Mohammadi Z, Havaee A. Evaluation of the antibacterial substantivity of several intracanal agents. Aust Endod J. 2006;32(3):112-5. doi:10.1111/j.1747-4477.2006.00033.x

7. Murray PE, Farber RM, Namerow KN, Kuttler S, Garcia-Godoy F. Evaluation of Morinda citrifolia as an endodontic irrigant. J Endod. 2008;34(1):66-70. doi:10.1016/j.joen.2007.09.016

8. Heitzman ME, Neto CC, Winiarz E, Vaisberg AJ, Hammond GB. Ethnobotany, phytochemistry and pharmacology of Uncaria (Rubiaceae). Phytochemistry. 2005;66(1):5-29. doi:10.1016/j.phytochem.2004.10.022

9. Santa Maria A, Lopez A, Diaz MM, Albán J, Galán de Mera A, Vicente Orellana JA, Pozuelo JM.

Evaluation of the toxicity of Uncaria tomentosa by bioassays in vitro. J Ethnopharmacol. 1997;57(3):183-7. doi:10.1016/S0378-8741(97)00067-6

10. Aquino R, De Feo V, De Simone F, Pizza C, Cirino G. Plant metabolites. New compounds and anti-inflammatory activity of Uncaria tomentosa. J Nat Prod. 1991;54(2):453-9. doi:10.1021/np50074a016

11. Herrera DR, Tay LY, Rezende EC, Kozlowski Jr VA, Santos EB. In vitro antimicrobial activity of phytotherapic Uncaria tomentosa against endodontic pathogens. J Oral Sci. 2010;52(3):473-6. doi:10.2334/josnusd.52.473

12. García R, Cayunao C, Bocic R, Backhouse N, Delporte C, Zaldivar M, et al. Antimicrobial activity of isopteropodine. Z Naturforsch C. 2005;60(5-6):385-8. doi:10.1515/znc-2005-5-603

13. Stuart CH, Schwartz SA, Beeson TJ, Owatz CB. Enterococcus faecalis: its role in root canal treatment failure and current concepts in retreatment. J Endod. 2006;32(2):93-8. doi:10.1016/j.joen.2005.10.049

14. Love RM. Enterococcus faecalis: a mechanism for its role in endodontic failure. Int Endod J. 2001;34(5):399-405. doi:10.1046/j.1365-2591.2001.00437.x

15. Shuping GB, Ørstavik D, Sigurdsson A, Trope M. Reduction of intracanal bacteria using nickel-titanium rotary instrumentation and various medications. J Endod. 2000;26(12):751-5. doi:10.1097/00004770-200012000-00022

16. Siqueira Jr JF, Roçâs IN, Paiva SSM, Guimarães-Pinto T, Magalhães KM, Lima KC. Bacteriologic investigation of the effects of sodium hypochlorite and chlorhexidine during the endodontic treatment of teeth with apical periodontitis. Oral Surg Oral Med Oral Pathol Oral Radiol Endod. 2007;104(1):122-30. doi:10.1016/j.tripleo.2007.01.027

17. Vianna ME, Horz HP, Conrads G, Zaia AA, Souza-Filho FJ, Gomes BPFA. Effect of root canal procedures on endotoxins and endodontic pathogens. Oral Microbiol Immunol. 2007;22(6):411-8. doi:10.1111/j.1399-302X.2007.00379.x

18. Martinho FC, Gomes BPFA. Quantification of endotoxins and cultivable bacteria in root canal infection before and after chemomechanical preparation with $2.5 \%$ sodium hypochlorite. J Endod. 2008;34(3):268-72. doi:10.1016/j.joen.2007.11.015

19. Rôças IN, Siqueira Jr JF. In vivo antimicrobial effects of endodontic treatment procedures as assessed by molecular microbiologic techniques. J Endod. 2011;37(3):304-10. doi:10.1016/j.joen.2010.11.003

20. Dametto FR, Ferraz CC, Gomes BPFA, Zaia AA, Teixeira $\mathrm{FB}$, Souza-Filho FJ. In vitro assessment of the immediate and prolonged antimicrobial action of chlorhexidine gel as an endodontic irrigant against Enterococcus faecalis. Oral Surg Oral Med Oral Pathol Oral Radiol Endod. 2005;99(6):768-72. doi:10.1016/j.tripleo.2004.08.026

21. Komorowski R, Grad H, Wu XY, Friedman S. Antimicrobial substantivity of chlorhexidinetreated bovine root dentin. J Endod. 2000;26(6):315-7. doi:10.1097/00004770-200006000-00001

22. Rosenthal S, Spångberg L, Safavi K. Chlorhexidine substantivity in root canal dentin. Oral Surg Oral Med Oral Pathol Oral Radiol Endod. 2004;98(4):488-92. doi:10.1016/j.tripleo.2003.07.005 